\title{
RADIATION-INDUCED SKIN PIGMENTATION AFTER ACCELERATED PARTIAL BREAST IRRADIATION: DOSE-VOLUME HISTOGRAM ANALYSIS
}

\author{
Alena Demianovich ${ }^{1^{*}}$, Dmitriy Sanin', Natalia Borysheva', \\ Valeriya Martynova', Sergey Ivanov', Andrey Kaprin²
}

${ }^{1}$ A. Tsyb Medical Radiological Research Centre - branch of the National Medical Research Radiological Centre of the Ministry of Health of the Russian Federation, Obninsk

${ }^{2}$ National Medical Research Radiological Centre of the Ministry of Health of the Russian Federation, Obninsk

\begin{abstract}
This research demonstrates the treatment of breast cancer with high dose rate (HDR) brachytherapy in the 34 Gy mode performed in 10 twice-a-day treatments, six hours apart over a period of five days. According to the protocol the maximum allowable radiation exposure for the skin did not exceed $34 \mathrm{~Gy}$. By May 2019, 28 patients were treated with a mean follow-up of 10.5 months, with the median of the study being 11 months. Among these patients, 7 had shown toxic effects on the skin in the form of pigmentation. For these patients parameters such as Dmax, Do.o1cc, Do.1cc, D1cc, and D2cc were analysed. Among the patients, some had the same values or higher but did not exhibit toxic effects. Therefore, the expected effects, as well as the results of treatment, are very individual and dependent on many factors. We can only try to minimise them. As a result, it is necessary to show care with values of Dmax $\geq 33$ Gy, Do.o1cc $\geq 32$, Do.1cc $\geq 30$, D1cc $\geq 27$ and D2cc $\geq 24$.
\end{abstract}

Keywords: Breast cancer, dosimetric parameters, high-dose-rate brachytherapy, radiation therapy, skin pigmentation, toxic effects

\section{INTRODUCTION}

Breast cancer (BC) is the most common malignant disease among women all over the world. The number of first time cases of cancer and the number of cancer deaths in 2018 are shown in Fig. 1 and 2 [1].

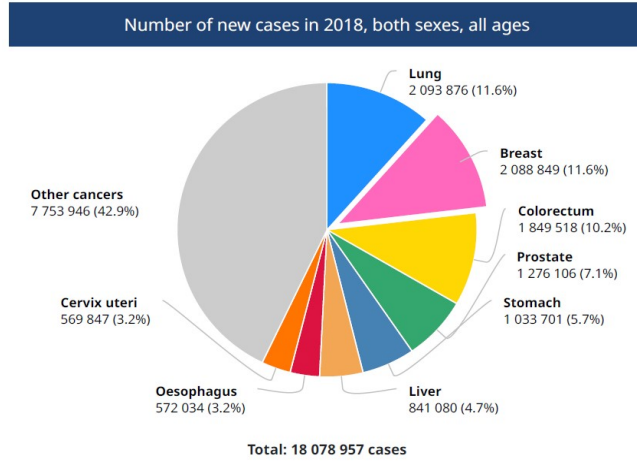

Figure 1. Number of new cases of breast cancer in 2018 according to the World Health Organisation

All types of BC treatment are divided into 2 main types: local (surgery, radiation therapy) and systemic (chemotherapy, hormonotherapy, immunotherapy).

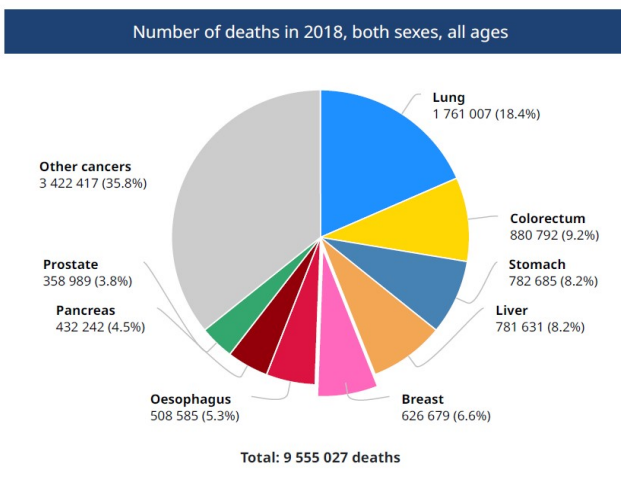

Figure 2. Number of deaths from breast cancer in 2018 according to the World Health Organisation

Surgery is not the only necessary part of the BC treatment because of the high risk of frequent relapses and distant metastases. That is why it is carried out in combination with, for example, postoperative radiotherapy.

The latest observations have shown a tendency that the age of patients with this diagnosis has been decreasing. Therefore, organ-preserving methods of treatment are becoming more and more relevant. Lumpectomy with subsequent multicatheter interstitial brachytherapy is the most promising treatment of this

*alyonadem1993@yandex.ru 
disease in its early stages. Thanks to this treatment, the time of postoperative therapy decreases several times. [2]. One of the main goals during the development of the method is to assess the biological radiation tolerance of the organs-at-risk (OARs), which include skin, ribs, lungs, heart and liver. The first two are closest to the target volume, so they received the most attention. Because of their proximity, the risk of toxic effects after irradiation is high. With regard to the skin, pigmentation of different grades is the main side effect (G). Since Accelerated Partial Breast Irradiation (APBI) is also used to achieve good cosmetic results, it is important to assess what doses lead to an increased risk of toxic effects.

A number of articles that describe different types of contouring of the skin were written. In addition, the articles discuss the skin radiation doses received after the APBI [3-11]. Almost all researchers reported a manifestation of pigmentation. However, these manifestations usually refer to the $\mathrm{G} 1-2$ and are considered acceptable.

This study presents around 7 cases of radiationinduced skin pigmentation after APBI based on the analysis of the dose-volume histograms (DVHs) of 28 patients.

\section{MATERIALS AND METHODS}

In 2017 the protocol for breast cancer treatment with a high dose rate (HDR) brachytherapy was adopted in A. Tsyb Medical Radiological Research Centre - branch of the National Medical Research Radiological Centre of the Ministry of Health of the Russian Federation. This protocol is the aforementioned mode of 34 Gy performed in 10 twicea-day treatments, six hours apart and over a period of five days.

The criteria (Table 1) for the selection of patients was chosen based on recommendations of GEC-ESTRO and the American Brachytherapy Society (ABS) and other studies conducted by foreign colleagues [2, 12, 13].

Every patient previously had an ultrasound (US) and computed tomography (CT) examination before lumpectomy. During the surgery, the tumor along with healthy tissue (at least one centimetre) and the sentinel lymph node was removed and the metal mark was installed into the tumour bed. It is important to note that catheters were installed during the open cavity surgery. In each case, a postoperative CT examination was carried out after which radiation therapy began.

BrachyVision treatment planning system (Varian, Palo Alto, CA, USA) and a device for contact radiation therapy (GammaMedplus iX HDR/PDR Aflerloader) (Varian, USA) with a 192Ir source were used for treatment planning.

The gross target volume (GTV) for evaluation consists of a nominal volume and the position of the tumor before surgery. These measures are highly similar to Imagine Related Target Volume (ImTV) and Estimated Tumour Bed (ETB) in GEC ESTRO recommendations [14]. The Clinical Target Volume (CTV) is defined as GTV plus $1 \mathrm{~cm}$ radial expansion and the Planning Target Volume (PTV) is CTV plus $0.5 \mathrm{~cm}$ for the purposes of avoiding target positioning. CTV and PTV are limited by the chest wall $5 \mathrm{~mm}$ away from the skin surface [15]. Fig. 3 shows the example of the irradiation target contour.

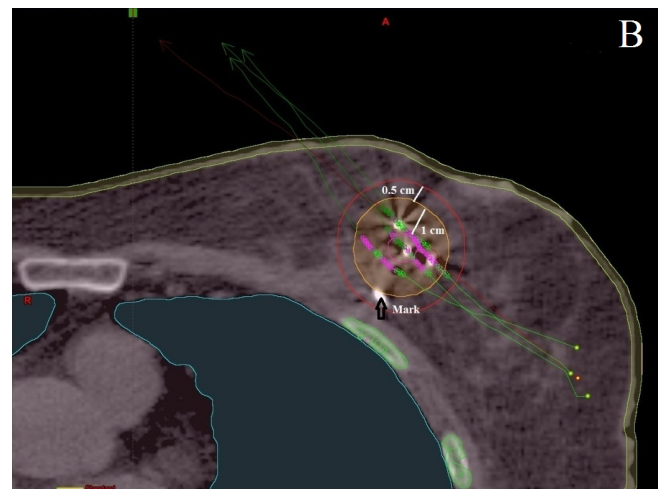

Figure 3. Example of the contouring of a patient after lumpectomy. The arrow shows the intraoperative mark. The purple line shows GTV, the orange line is CTV and the red line is the contour of PTV

As OAR, the skin was drawn $3 \mathrm{~mm}$ inside from the body surface. During treatment planning, all attempts were made to limit the maximum dose $\left(D_{\max }\right)$ applied to the skin to less than $100 \%$ dose. The main criterion for plan approving was the coverage parameter $\mathrm{V} 90 \geq$ $90 \%$ of the total PTV.

Doses were normalised following international standards. They were converted into an equivalent dose of 2 Gy per fraction $\left(\mathrm{EQD}_{2}\right)$ using Formula 1.

$$
\mathrm{EQD}_{2}=\mathrm{n} \times \mathrm{d} \times \frac{\mathrm{d}+\left(\frac{\alpha}{\beta}\right)}{2+\left(\frac{\alpha}{\beta}\right)}
$$

where $\mathrm{n}$ is the number of fractions, $\mathrm{d}$ is the dose per fraction (in Gy), and $\alpha / \beta$ is 3 for OARs and 4 for the tumour.

After the treatment of 28 patients, 7 of them had the G1 skin pigmentation. To establish the relationship between these toxic effects and the doses received by this OAR, an analysis of the DVH results of all patients was carried out. It did not consist only of the protocol parameter Dmax but also of other volumetric parameters. These included $\mathrm{D}_{\text {o.o1cc, }} \mathrm{D}_{0.1 \mathrm{cc}}, \mathrm{D}_{1 \mathrm{cc}}$ and $\mathrm{D}_{2 \mathrm{ccc}}$.

\section{RESULTS}

By May 2019, 28 patients were treated with a mean follow-up of 10.5 months and the study median of 11 months. Among these patients, 7 had shown toxic effects on the skin in the form of pigmentation. The results of the dose-volume histogram (DVH) were analysed.

Dmax values to the skin for all patients are presented in Fig.4. 


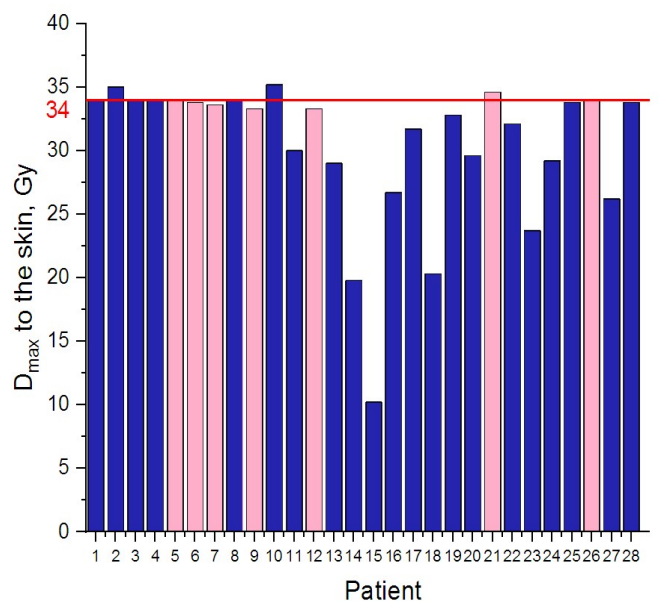

Figure 4. $D_{\max }$ to the skin for all 28 patients

As can be seen from Fig.3, doses of three patients (2, 10 and 21) exceeded values of the maximum dose limit. The fact that only 1 of them had pigmentation is of interest. At the same time, another 6 patients 5-7, 9, 12 and 26 (highlighted in pink), whose $\mathrm{D}_{\max }$ was lower or equal to the permissible maximum of radiation exposure showed toxic effects. The patient 10 received the maximal skin dose of $1.2 \mathrm{~Gy}$. The values of patients with toxic effects ranged from 34.6 to $33.3 \mathrm{~Gy}$ ( $33.8 \pm$ 0.42 Gy averaged). Maximal $\mathrm{EQD}_{2}$ for these patients was $44.7 \mathrm{~Gy}$ and minimal was $42.2 \mathrm{~Gy}(43.1 \pm 0.8 \mathrm{~Gy}$ averaged).

In order to have a complete picture and find more accurate parameters for the prediction of toxic effects, it was necessary to perform an estimation of the volume dose ( $\mathrm{D}_{\text {o.o1cc, }}, \mathrm{D}_{\mathrm{o} .1 \mathrm{cc}}, \mathrm{D}_{1 \mathrm{cc}}$ and $\mathrm{D}_{2 \mathrm{cc}}$ ), which are presented in Table 1.

Table 1. Values of the volumetric dosimetric parameters to the skin

\begin{tabular}{|c|c|c|c|c|}
\hline Patient & $D_{\text {o.o1cc }}, \mathrm{Gy}$ & $\mathrm{D}_{\text {o.1cc }}, \mathrm{Gy}$ & $\mathrm{D}_{1 \mathrm{cc}}, \mathrm{Gy}$ & $\mathrm{D}_{2 \mathrm{cc}}, \mathrm{Gy}$ \\
\hline \multicolumn{5}{|c|}{ Patients with skin pigmentation } \\
\hline 5 & 33 & 31 & 27 & 24 \\
6 & 31 & 29 & 24 & 20 \\
7 & 32 & 30 & 27 & 25 \\
9 & 32 & 30.4 & 27 & 24 \\
12 & 32 & 30 & 26 & 23 \\
21 & 33.4 & 31.8 & 29 & 27.7 \\
26 & 33 & 32 & 27 & 26 \\
\hline Patients with exceeded maximum dose and without \\
\multicolumn{5}{|c|}{ skin pigmentation } \\
\hline 2 & 28 & 22 & 16 & 15 \\
10 & 34 & 32 & 27 & 25 \\
\hline
\end{tabular}

Mean $\mathrm{D}_{\text {o.o1cc }}$ to the skin was $32.34 \pm 0.77 \mathrm{~Gy}$ and its $\mathrm{EQD}_{2}$ was equal to $40.2 \mathrm{~Gy}$. At the same time, $\mathrm{D}_{\text {o.1cc }}=$ $30.6 \pm 1.0 \mathrm{~Gy}\left(\mathrm{EQD}_{2}=37.1 \mathrm{~Gy}\right) ; \mathrm{D}_{1 \mathrm{cc}}=26.7 \pm 1.6 \mathrm{~Gy}$ $\left(\mathrm{EQD}_{2}=30.3\right)$ and $\mathrm{D}_{0.1 \mathrm{cc}}=24.2 \pm 2.2 \mathrm{~Gy}\left(\mathrm{EQD}_{2}=\right.$ 23.5).

Two patients with the doses that exceed $(2,10)$ the $D_{\max }$ parameter were analysed separately (Table 1$)$. So, patient 2 had $\mathrm{D}_{\mathrm{o}, 01 \mathrm{cc}}: 28 \mathrm{~Gy}\left(\mathrm{EQD}_{2}=32.5 \mathrm{~Gy}\right), \mathrm{D}_{\mathrm{o}, 1 \mathrm{cc}}: 22$ Gy $\left(\mathrm{EQD}_{2}=22.9 \mathrm{~Gy}\right), \mathrm{D}_{1 \mathrm{cc}}: 16 \mathrm{~Gy}\left(\mathrm{EQD}_{2}=14.7 \mathrm{~Gy}\right)$ and $D_{2 c c}: 15$ Gy $\left(E_{2 D}=13.5 \mathrm{~Gy}\right)$. The values for patient 10 were $D_{0,01 c c}: 34 \mathrm{~Gy}\left(\mathrm{EQD}_{2}=43.5 \mathrm{~Gy}\right), \mathrm{D}_{\mathrm{o}, 1 \mathrm{cc}}: 32 \mathrm{~Gy}$ $\left(\mathrm{EQD}_{2}=39.7 \mathrm{~Gy}\right), \mathrm{D}_{1 \mathrm{cc}}: 27 \mathrm{~Gy}\left(\mathrm{EQD}_{2}=30.8 \mathrm{~Gy}\right)$ and $\mathrm{D}_{2 \mathrm{cc}}: 25 \mathrm{~Gy}\left(\mathrm{EQD}_{2}=27.5 \mathrm{~Gy}\right)$.

Finally, to complete the picture understanding, there are mean dose values for all 28 patients below:

$$
\begin{aligned}
& -\mathrm{D}_{\max }=30.4 \pm 2.3 \mathrm{~Gy}\left(\mathrm{EQD}_{2}=36.7 \mathrm{~Gy}\right) ; \\
& -\mathrm{D}_{0.01 \mathrm{cc}}=28.6 \pm 2.1 \mathrm{~Gy}\left(\mathrm{EQD}_{2}=33.5 \mathrm{~Gy}\right) ; \\
& -\mathrm{D}_{0.1 \mathrm{cc}}=26.4 \pm 2.0 \mathrm{~Gy}\left(\mathrm{EQD}_{2}=29.8 \mathrm{~Gy}\right) ; \\
& -\mathrm{D}_{1 \mathrm{cc}}=21.9 \pm 2.1 \mathrm{~Gy}\left(\mathrm{EQD}_{2}=22.7 \mathrm{~Gy}\right) ; ; \\
& -\mathrm{D}_{2 \mathrm{cc}}=19.7 \pm 1.9 \mathrm{~Gy}\left(\mathrm{EQD}_{2}=19.6 \mathrm{~Gy}\right) ;
\end{aligned}
$$

So, it can be noted that when the maximum dose limit was exceeded, patient 2 had lower values of volumetric doses compared with patients with skin pigmentation and mean dose values of all patients. At the same time, $D_{0.01 c c}, D_{0.1 c c}, D_{1 c c}$ and $D_{2 c c}$ parameters of the patient 10 are similar to patients with toxic effects. But compared with mean data, his values are higher.

\section{CONCLUSION}

The expected effects, as well as the results of treatment, are very individual and depend on many factors.

Based on our results, it appears that, when it comes to maximal permissible doses, we should assess the maximal setting as volumetric in order to predict toxic effects. So, it is necessary to be careful with values of $D_{\max } \geq 33$ Gy, $D_{\text {o.o1cc }} \geq 32, D_{0.1 c c} \geq 30, D_{1 c c} \geq 27$ and $D_{2 c c}$ $\geq 24$.

Nevertheless, given the limited number of patients involved in the investigation and the short follow-up period, this study should be continued with the selection criteria and radiation exposure restrictions perhaps reviewed in the future.

Acknowledgements: The authors are grateful to the researcher $R$. Mikailova from the Russian Institute of Radiology and Agroecology for the help in the preparation of this paper.

\section{REFERENCES}

1. Breast, IARC, Lyon, France, 2018. Retrieved from: https://gco.iarc.fr/today/data/factsheets/cancers/20Breast-fact-sheet.pdf Retrieved on: Nov. 15, 2018

2. J. A. Latorre et al., "Accelerated partial breast irradiation in a single 18 Gy fraction with high-dose-rate brachytherapy: preliminary results," J. Contemp. Brachytherapy, vol. 10, no. 1, pp. 58 - 63, Feb. 2018.

DOI: $10.5114 /$ jcb.2018.73994

PMid: 29619057 PMCid: PMC5881592

3. S. Ahmad et al., "Comparison of tumor and normal tissue dose for accelerated partial breast irradiation using an electronic brachytherapy eBx source and an Iridium-192 source," J. Appl. Clin. Med. Phys., vol. 11, no. 4, pp. 155 161, Sep. 2010.

DOI: 10.1120/jacmp.v11i4.3301

PMid: 21081891

PMCid: PMC5720398 
4. M. Sinnatamby, V. Nagarajan, R. K. Sathyanarayana, G. Karunanidhi, V. Singhavajala, "Study of the dosimetric differences between 192Ir and 6oCo sources of high dose rate brachytherapy for breast interstitial implant," Rep. Pract. Oncol. Radiother., vol. 21, no. 5, pp. 453 - 459, Sep.Oct. 2016.

DOI: 10.1016/j.rpor.2016.03.005

PMid: 27489516

PMCid: PMC4949742

5. M. Oshaghi, M. Sadeghi, S. R. Mahdavi, A. R. Shirazi, "A Comparison of Skin Dose Delivered with MammoSite and Multicatheter Breast Brachytherapy," J. Biomed. Phys. Eng., vol. 3, no. 4, pp. 133 - 138, Dec. 2013. PMid: 25505759 PMCid: PMC4204506

6. J. Lasota, R. Kabacińska, R. Makarewicz, "Dose estimation for different skin models in interstitial breast brachytherapy," J. Contemp. Brachytherapy, vol. 6, no. 2, pp. 200 - 207, Jun. 2014.

DOI: $10.5114 /$ jcb.2014.43167

PMid: 25097562

PMCid: PMC4105640

7. K. Yoshida et al., "Case report of a dose-volume histogram analysis of rib fracture after accelerated partial breast irradiation: interim analysis of a Japanese prospective multi-institutional feasibility study," J. Contemp. Brachytherapy, vol. 10, no. 3, pp. 274 - 278, Jun. 2018.

DOI: $10.5114 /$ jcb.2018.76983

PMid: 30038649

PMCid: PMC6052388

8. G. L. Smith et al., "Association between treatment with brachytherapy vs whole-breast irradiation and subsequent mastectomy, complications, and survival among older women with invasive breast cancer," JAMA Oncol., vol. 307, no. 17, pp. 1827 - 1837, May 2012.

DOI: 10.1001/jama.2012.3481

PMid: 22550197

PMCid: PMC3397792

9. J. Huo, S. H. Giordano, B. D. Smith, S. F. Shaitelman, G. L. Smith, "Contemporary Toxicity Profile of Breast Brachytherapy Versus External Beam Radiation After Lumpectomy for Breast Cancer," Int. J. Radiat. Oncol. Biol. Phys., vol. 94, no. 4, pp. 709 - 718, Mar. 2016.

DOI: 10.1016/j.ijrobp.2015.12.013

PMid: 26972643
10. J. W. Snider et al., "Projected Improvements in Accelerated Partial Breast Irradiation Using a Novel Breast Stereotactic Radiotherapy Device: A Dosimetric Analysis," Technol. Cancer Res. Treat., vol. 16, no. 6, pp. 1031 - 1037, Jan. 2017.

DOI: $10.1177 / 1533034617718961$

PMid: 28705082

PMCid: PMC5762064

11. M. Akhtari et al., "Clinical outcomes, toxicity, and cosmesis in breast cancer patients with close skin spacing treated with accelerated partial breast irradiation (APBI) using multi-lumen/catheter applicators," J. Contemp. Brachytherapy, vol. 8, no. 6, pp. 497 - 504, Dec. 2016.

DOI: $10.5114 /$ jcb.2016.64830

PMid: 28115955

PMCid: PMC5241383

12. V. Strnad et al., "ESTRO-ACROP guideline: Interstitial multi-catheter breast brachytherapy as Accelerated Partial Breast Irradiation alone or as boost - GEC-ESTRO Breast Cancer Working Group practical recommendations," Radiother. Oncol., vol. 128, no. 3, pp. 411 - 420, Sep. 2018.

DOI: 10.1016/j.radonc.2018.04.009 PMid: 29691075

13. C. Shah et al., "The American Brachytherapy Society consensus statement for accelerated partial-breast irradiation," Brachytherapy, vol. 12, no. 4, pp. $267-277$, Jul.-Aug. 2013.

DOI: 10.1016/j.brachy.2013.02.001

PMid: 23619524

14. V. Strnad et al., "Recommendations from GEC ESTRO Breast Cancer Working Group (I): Target definition and target delineation for accelerated or boost Partial Breast Irradiation using multicatheter interstitial brachytherapy after breast conserving closed cavity surgery," Radiother. Oncol., vol. 115, no. 3, pp. 342 - 348, Jun. 2015.

DOI: 10.1016/j.radonc.2015.06.010 PMid: 26104975

15. T. Majora, et al, "Recommendations from GEC ESTRO Breast Cancer Working Group (II): Target definition and target delineation for accelerated or boost partial breast irradiation using multicatheter interstitial brachytherapy after breast conserving open cavity surgery," Radiother. Oncol. vol. 118, no. 1, pp. 199 - 204, Jan. 2016.

DOI: $10.1016 /$ j.radonc.2015.12.006

PMid: 26776444 